\title{
Energy Consumption, Economic Growth, and Environmental Degradation in OECD Countries
}

\author{
Dong Kyun Kim \\ Pacific University, USA. \\ Email:_onghvun.Kim@pacificu.edu
}

\begin{abstract}
The world is governed by the issues of environmental degradation, climate control, pollutant emissions and other such phenomena due to the increasing dilapidation of environmental resources. For a while now, the focus has been on the production of green technologies, clean energy solutions and the development of a sustainable module that will aid in the restoration and protection of the environment. In this scenario, the dependence on consumption patterns of energy, economic growth (EG), and environmental degradation (ED) have become the focus of many researchers and policymakers. The Organization for Economic Co-operation and Development (OECD) countries are understandably characterized as the fastest developing nations of the world. However, literature evaluating the influence of energy consumption (EC) and economic growth (EG) on environmental degradation has presented conflicting results. This study aims to solve this conflict by presenting a panel dataset comprised of 35 OECD between 2000-2014. The Generalized Method of Moments Panel Vector Autoregression (GMM-PVAR) has been used to estimate the impact and causal relationship between the variables. The results of the study indicate that EG and consumption patterns of energy are vital for the improvement of the environmental performance of the firms. In contrast to other empirical literature, this study finds that the economic development of the country or countries and the patterns of consumption have started to coagulate with set environmental performance parameters. Environmental policies, consumption patterns and plans for EG are all being aligned in OECD countries. The results of this study are robust, as different methods for the evaluation have been used.
\end{abstract}

Keywords: GMM-PVAR, Granger Causality, OECD.

Citation | Dong Kyun Kim (2020). Energy Consumption, Economic Growth, and Environmental Degradation in OECD Countries. Asian Journal of Economics and Empirical Research, 7(2): 242-250. History:

Received: 9 July 2020

Revised: 13 August 2020

Accepted: 16 September 2020

Published: 29 September 2020

Licensed: This work is licensed under a Creative Commons

Attribution 3.0 License $(\mathrm{cc})$ )

Publisher: Asian Online Journal Publishing Group
Funding: This study received no specific financial support.

Competing Interests: The author declares that there are no conflicts of interests regarding the publication of this paper.

Transparency: The author confirms that the manuscript is an honest, accurate, and transparent account of the study was reported; that no vital features of the study have been omitted; and that any discrepancies from the features of the study have been omitted
study as planned have been explained.

study as planned have been explained.
Ethical: This study follows all ethical practices during writing.

\section{Contents}

1. Background

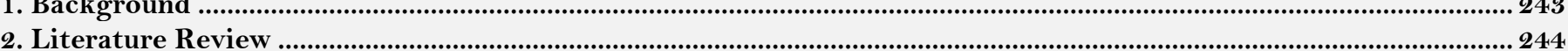

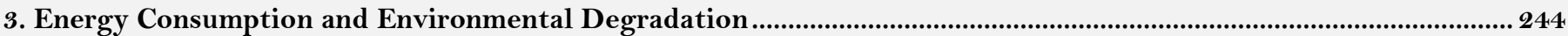

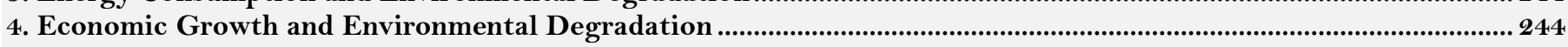

5. Method .....

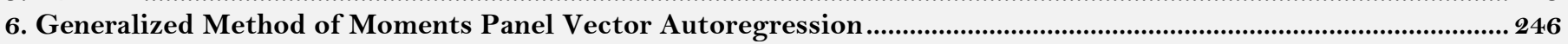

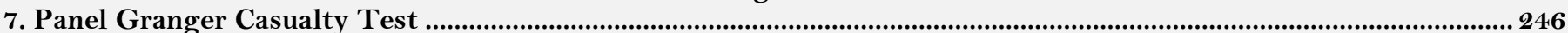

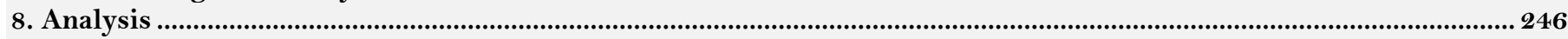

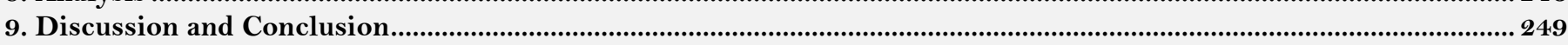

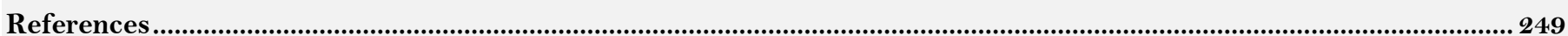




\section{Contribution of this paper to the literature}

This study contributes to existing literature by empirically testing the association among energy consumption, economic growth, and environmental degradation in 35 OECD between 2000-2014.

\section{Background}

There somehow exists a positive relationship between energy consumption (EC) and economic growth (EG), as an increase in one variable results in an increase in the rate of another variable in OECD countries (Kahouli, 2019). However, environmental degradation (ED), such as the pollution of land or water, results in a decreasing EG of a country, as well as effects such as the consumption of carbon dioxide gas, air pollutants, the consumption of fish and crops, and changes in land-use, which add to the degradation of the environment (Zafar, Shahbaz, Sinha, Sengupta, \& Qin, 2020). Although ED results in an increase in income per capita up to a certain threshold, the EG of a country affects its performance level with regard to the environment, as the pure EG of a country increases the level of ED if a country is unable to change their structures in terms of their technology and economy (Destek \& Sinha, 2020).

The environmental situation and ED has been considerably gaining attention from academic practitioners over the past few decades (Destek \& Sinha, 2020). It has been noted by different researchers and analysts that, even now, an environmental performance and ED gap exists in different European countries, as several nations and regions have consume a lot of energy in the past few decades (Raza, Shah, \& Sharif, 2019). Mbarek, Saidi, and Rahman (2018) have suggested that, in order to respond to the limitations and gaps in the current literature, the contextual variables and factors impacting the overall environmental situation need to be identified and investigated in detail, as research efforts on ED and the ecological effects of EG are sparse; therefore, studies needs to be carried out on the environmental situation in OECD nations (Gorus \& Aydin, 2019). Zafar, Saud, and Hou (2019) have identified the impact of social factors, Balsalobre-Lorente, Driha, Shahbaz, and Sinha (2020) have examined the impact of humidity and organisms, and Bekhet, Matar, and Yasmin (2017) have investigated the impact of biotic and biotic factors. Thus, the overall and detailed understanding of EC and EG factors from the perspective of ecological changes are significant. In order to respond to such restrictions in the academic research, the present paper investigates the impact of several EC and EG factors from the perspective of OECD countries through a unique and effective integration of variables using modern statistical methods and techniques. To the knowledge of the analyst, this is the first and unique study of its kind. The graph below indicates the percentage of EC in certain sectors in OECD countries.

\section{Energy Consumption by Sector, OECD Countries}

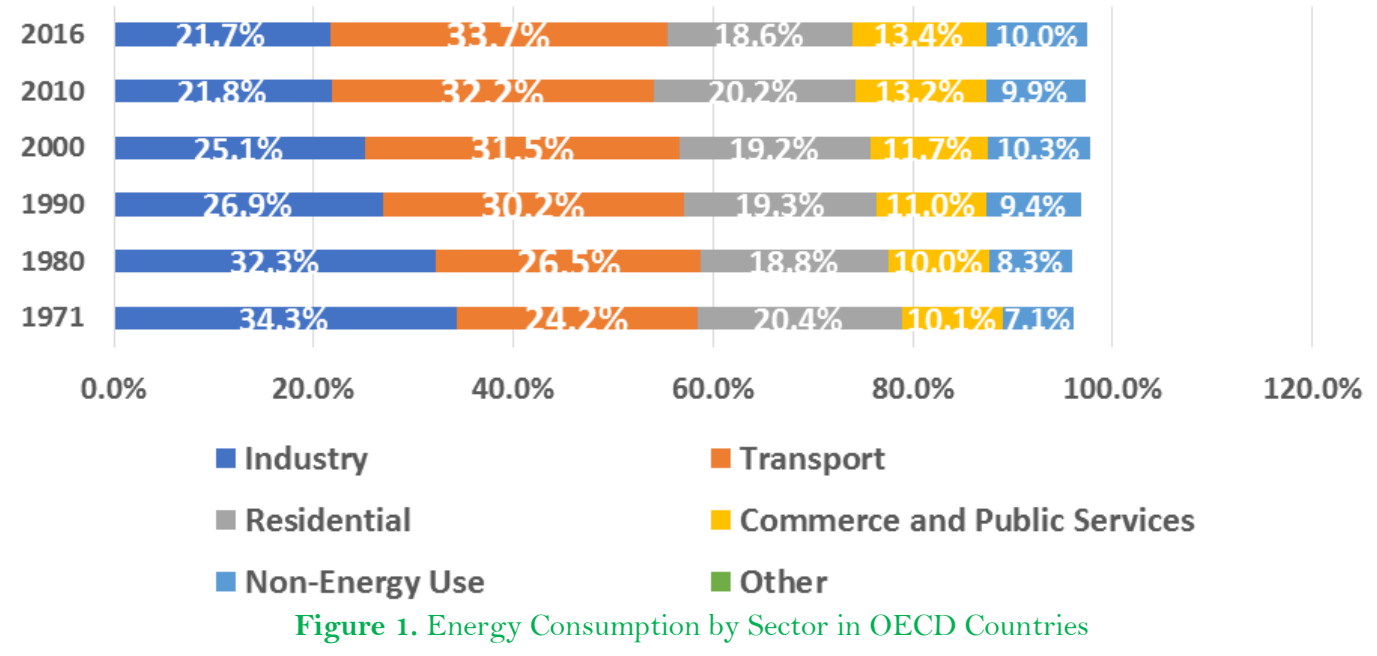

The main purpose of the present research thesis is to empirically investigate the overall impact of EC factors on the ED of OECD regions, and the second major aim of this paper is to analyze the exclusive impact of the EG of different OECD countries on the degree of ED and related concepts and situations. Moreover, the current research paper also investigates the correlation between EG and EC and how this nexus further affects the environment in OECD regions. In line with the above objectives, the given study poses the following research questions: What is the total impact of EC on ED in OECD states, and how does the EG of several states affect ED and related factors.

Like all studies and empirical findings, this effort has profound advantages and insights in both theory and practice. Practically, the findings of this study are beneficial for academic scholars and experts, as well as policymakers who have to promote educational ecological models for different industries and sectors that consume energy and other hazardous materials, in order for more industries and sectors to be encouraged to use and adopt environmental regulations (Amir \& Chaudhry, 2019). Such research concerned with ecological concepts can build significant and favorable perceptions of environmental development in societies, as well as navigating the society of different OECD states towards improvement. Theoretically, the overall results and outcomes of this paper contribute to the current framework of information by analyzing the underlying process through computing the influence of EC and EG on the ED of certain states. Furthermore, this paper adds to the current body of research in several ways, as most of the previous research efforts only used carbon dioxide releases as intermediaries for ecological damage. In contrast, the present study uses a country's ecological footprint (EF) and ecological performance index (EPI) to represent several types of environmental pollution.

The remainder of the research is organized as follows: Section two presents the practices and concepts of EPI and EF calculations; Section three provides information on the overall methodological design used by the analyst for data collection; Section four presents all empirical and observed findings; and section five concludes the paper and presents the implications and limitations of the study, as well as providing suggestions for future research. 


\section{Literature Review}

According to this theory, ED and damage is the disintegration of the earth and deterioration of conditions as a result of the consumption of energy and other resources such as air, soil, and water (Majeed \& Luni, 2019). According to Majeed and Mumtaz (2017), ED is generally characterized as any modifications or destruction to nature's turf that is seen to be undesirable and pernicious. This theory also states that ecological destruction and its effects are largely generated by the unification of substantial and growing human activities, such as EC, (Oktavilia \& Firmansyah) continuously increasing economic growth and wealth per capita, and the effects of resource destruction and technological procedures and practices. According to Alvarado and Toledo (2017), ED is the destruction of ecological conditions through the depletion of assets such as minerals and soil, which leads to the complete deterioration of ecosystems and habitat destruction. Specifically, this theory states that ED only happens when the earth's natural resources are depleted for economic activities and growth. ED is one of the largest issues and threats that is considered in global activities today. This theory and model characterizes ED as the decline of the limit of the earth to achieve environmental and economic destinations and requirements. According to Alvarado, Ponce, Criollo, Córdova, and Khan (2018), ED can occur in a number of ways; initially, environments are harmed and fundamental resources are exhausted for economic and fiscal goals, and then the overall environment is considered to be disrupted and harmed. However, certain significant methods and procedures have been adopted to prevent this, including common protection efforts and environmental asset protection practices. Moreover, this theory demonstrates that excessive EC is the major cause of ED because excessive EC is a condition whereby the use of assets has surpassed the capacity of the entire ecosystem. According to Ogundipe, Obi, and Ogundipe (2020), this is generally measured using $\mathrm{EF}$, which is a resource management concept used to compare the individual needs of ecosystems with the volume of ecosystems that can be renewed (Usman, Olanipekun, Iorember, \& AbuGoodman, 2020).

\section{Energy Consumption and Environmental Degradation}

According to Raza et al. (2019), all energy assets have some influence on the environment; fossil fuels such as oil, natural gas, and coal do substantially more damage than renewable energy sources, mainly through air and water pollution that can damage an individual's health. According to Sinha, Shahbaz, and Balsalobre (2017), habitat and wildlife loss, land use, and global warming $(\mathrm{GW})$ increases. Renewable assets, on the other hand, such as hydropower, solar, biomass, wind, and geothermal, also have direct environmental impacts and influences - some of which are favorable (Sekrafi \& Sghaier, 2018). According to Sharif and Raza (2016), the right dimension and degree of environmental impacts varies depending on certain technological processes, geographic locations, and several other variables and factors. In OECD nations, the environmental impact of energy harvesting and consumption is diverse. Recently, Sharif et al. (2020) illustrated that, in recent years, there has been a trend towards the improved commercialization of several renewable energy assets. In a real sense, the consumption of fossil fuel predominantly leads to GW and climate change. Although certain changes are being made in several states and regions of OECD, biodiesel consumption is still the main source of ED in OECD nations, according to Ahmad et al. (2020); Mbarek et al. (2018), The environmental influence of biodiesel involves the releasing of greenhouse gases, energy usage, and certain other types of pollution. According to recent statistics by OECD nations and the British department of energy, substituting $100 \%$ of biodiesel used for petroleum purposes in buses minimized the lifecycle consumption of petroleum by $95 \%$. Thus, biodiesel minimized the net release of $\mathrm{CO}_{2}$ by $77.45 \%$, compared to petroleum diesel. Coal mining and burning are other major sources of ED in OECD regions. The environmental impact of electricity generation is significant in OECD regions because modern societies use large amounts of electrical power. Therefore, based on the entire above discussion, the study proposes the following hypothesis:

H1: EC directly and positively relates to ED in several states.

\section{Economic Growth and Environmental Degradation}

ED is the deterioration of the environment through the exhaustion of resources such as water, air and soil, pollution, habitat destruction, the destruction of the ecosystem, pollution, and the disintegration of the earth's resources. ED is either a consequence or driver of disasters, which causes a reduction in the capacity of the environment to meet ecological or social needs. Over usage or the excessive consumption of natural resources may result in ED, which is essentially the reduction in the earth's capacity to meet social and ecological objectives. This act of degradation and the associated decay of ecosystems and their invaluable services means that the advantages or benefits that humans obtain are a driving force of deforestation, landslides, and the removal of mangroves. EG plays a major role in improving facilities and meeting basic human needs, as well as providing lifestyle improvements, luxuries and leisure activates. Construction is improved and the demands and priorities of life change (Adu and Denkyirah, 2018). This is because of the fact that humans around the globe have become accustomed to luxuries, modern vehicles, and the availability of all the latest technical objects, electronic items, and facilities. Growing industries have become a constant source of ED, as meeting needs and demands has led to the establishment of mega factories, which has become a major reason for deforestation and environmental pollution. According to Saidi and Hammami (2017), countries with a better economy have become accustomed to using certain machines and electric equipment that make their life easier; however, this creates global problems such as environmental issues. EG indicates that a country is achieving milestones and making progress in the field of industry, agriculture and business. However, this cycle of progress brings satisfaction and an urge to go beyond certain limits by obtaining technical and electrical accessories. Developed economic countries also make plans to experiment with scientific ideas, which also causes environmental degradation. It is also very alarming that the population of the world is increasing rapidly (Rahman, 2020; Usman, Alola, \& Sarkodie, 2020). This rise in population means that certain resources will be in demand in order to maintain a good standard of life, such as new homes, schools, vehicles, and demands for the luxuries of life. This all creates a negative impact, as the consumption of natural resources increases and there is currently no replacement process. According to Balsalobre-Lorente, Shahbaz, Roubaud, and Farhani (2018), it is very clear that EG creates chances for ED, as they have access to every 
resource to use as their own. This situation creates a complicated scenario, as EG signifies the positive development of the economy; however, it also causes issues that influence the environment and create ED; thus, the link between EG and ED is very clear. The circumstances created under EG are not interrelated and positive with the condition of the environment. Thus, the above discussion leads to the development of the following hypothesis: H2: There is a direct and positive relationship between EG and ED.

\section{Method}

In the present research, we examined a sample of thirty-five OECD countries between the years 2000 to 2014. This research makes use of two empirical models to determine the relationship between the consumption of energy, the growth of economy and the degradation of the environment. The study uses GDP, $\mathrm{CO} 2$ emissions or environmental indexes (EPI and EF), and EC. Two different models have been used in the study to evaluate the significant relationship between consumption, growth and degradation patterns in the economies of OECD countries. The first model uses the inputs on GDP, $\mathrm{CO} 2$ emissions, and EC, and the second model includes the variables of EF, GDP, and EC. The subsequent units of the variables are EC per capita equivalent of a kilogram of oil, $\mathrm{CO} 2$ emissions (measured in metric tons per capita), and the variable GDP (measured in millions, constant 2011 international USD \$). With regard to the variable of an environmental index, the EPI data has been collected from sources from the Yale center for Economical Law \& Policy and the EF data has been pulled from the Global Footprint Network.

Figure 1 presents the variables that were used in the research. The figure presents a scatter diagram of the highlighted variables, focusing on the basic relationships. Furthermore, the green and red lines show the parametric and non-parametric interconnections between the examined variables. In order to properly understand the connections between GDP, EPI, EC, EF, and $\mathrm{CO} 2$ emissions, the full outcomes are shown in Figure 1. The density plot of the variables represents the distribution of every variable over the entire time period. We can see the difference between the different patterns of all variables used in this study. For example, $\mathrm{CO} 2$ emissions had a positive impact on GDP, but a negative impact on EPI and EF. If we look at the density distribution plot of $\mathrm{CO} 2$ emissions, it shows a bimodal distribution. This distribution is explained by two clear points in the approximated density function. These findings indicate that, within the sample, there are two clear categories of countries in terms of $\mathrm{CO} 2$ levels. The overall image implies a deeper examination of the discovered connections between the variables that were employed in the study. It has been observed from the results that the mean value of EPI varies between the period of 2011 to 2014. The main reason behind this change is that the calculations from 2011 onwards were created using the new environmental trend index, EPI. This new EPI includes the environmental policies of countries. Data were obtained from the Millennium Development Goal Seven and the Earth Summit, which took place in Rio in 1992 (Hsu, Lloyd, \& Emerson, 2013).

\section{Scatterplot Matrix}
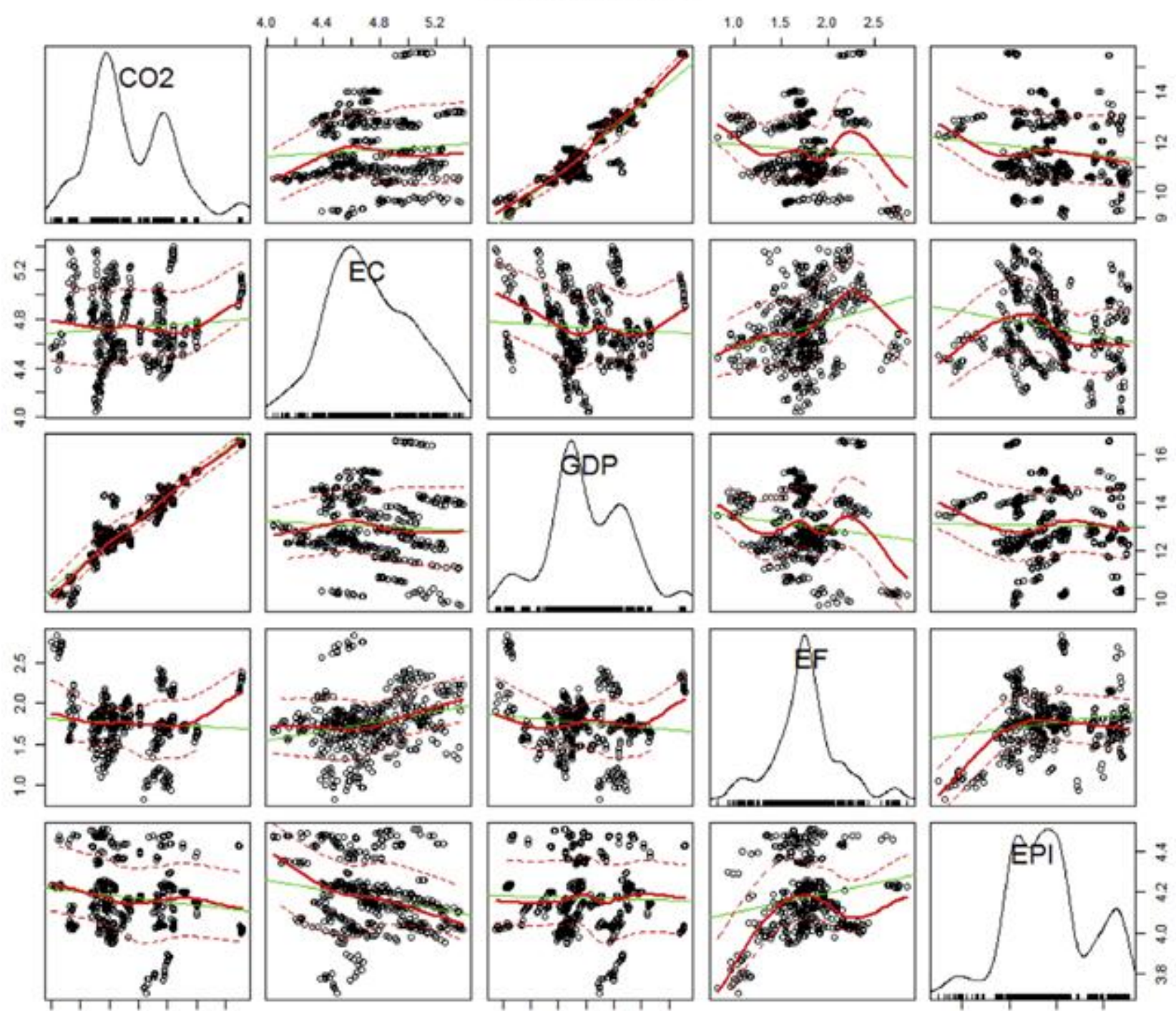

$\begin{array}{llllllll}10 & 11 & 12 & 13 & 14 & 15 & 16\end{array}$

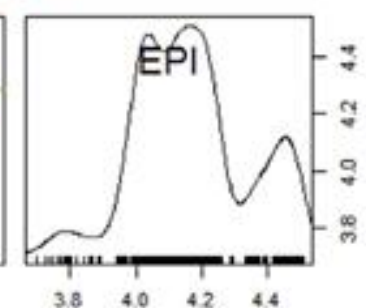

Figure-2. Scatterplot matrix 


\section{Generalized Method of Moments Panel Vector Autoregression}

As this study applied the GMM-PVAR methodology, the panel data has to be stationary. For this reason, the study used panel data tests developed by Im, Pesaran, and Shin (2003) and Pesaran (2007). The assumption is that the variables will be stationary either at level or at the first difference so that the model for the GMM-PVAR method can be designed. The model is expressed as follows:

$$
x_{i t}=\left(L_{n}-\sum_{l=1}^{P} A_{1}\right) n_{i}+\sum_{l=1}^{p} A_{l} x_{i, t-1}+Z x_{i, t}+V f_{i t}+u_{i t}
$$

In the above equation, the term $x_{i t}$ is the main endogenous variable on the time t, the variable $x_{i, t-1}$ expresses the presence of a lagged constituent in the endogenous variable, the term $L_{n}$ signifies the nxn matrix, and the variables $\mathrm{A}, \mathrm{Z}$ and $\mathrm{V}$ have been used as parameters for homogeneity. The term $\mathrm{f}$ is used to display the vector of exclusive exogenous variates. The term $u$ denotes the error term that is assumed to be independent. The method proposes the use of two processes for the estimation of fixed effects, where the first difference allows for the fixation of the problems imposed by the fixed effects. However, these issues can be omitted by using the GMM method. In particular, if the transformation matrix is used and applied on the converted covariates and lagged estimators, the variables can be used as coefficients for the instrumental regressors by applying the GMM estimator.

\section{Panel Granger Casualty Test}

The Granger casualty test was adopted by the author after the estimation of coefficients of variables and the long-term relationships between them. The basic purpose of these tests is to find out the existence and direction of any causal relationship between variables (Dumitrescu \& Hurlin, 2012). These tests are generally performed for each cross section of the data in order to generate results in the form of test statistics. This test is also based on the process of a null and alternate hypothesis that indicates the absence and presence of casual relationships, respectively. A general equation for this test can be given as follows:

\section{Analysis}

$$
\begin{gathered}
x_{t}=\sum_{i=1}^{\infty} a_{i} x(t-i)+c_{1}+\mu_{1(t)} \\
x_{t}=\sum_{i=1}^{\infty} a_{i} x(t-i)+\sum_{j=1}^{\infty} b_{j} y(t-j)+c_{2}+\mu_{2(t)}
\end{gathered}
$$

First, we evaluated the stationary aspect of the covariates involved in the study for both models used. Table 2 shows the stationarity of the variables. The two-panel unit root test indicates that all variables (GDP), (EPI), (EF), $(\mathrm{CO} 2)$ releases, and (EC) are integrated of order one. More precise data in Table 1 describes the results of the stationarity test; however, when we examine the results derived from the panel unit root test, the outcomes appear to be stationary in the first variation.

\begin{tabular}{c|c|c|c|c|c|c}
\hline \multicolumn{7}{c}{ Table 1. Stationarity test } \\
\hline \multirow{2}{*}{ Level } & t-bar & 1.022 & GDP & CO $_{2}$ & EF & EPI \\
\hline Pesaran & p-value & 0.212 & 0.202 & 0.862 & 1.123 & 2.512 \\
\hline \multirow{2}{*}{ Im } & t-bar & 3.913 & 3.622 & 3.522 & 5.433 & 8.001 \\
\cline { 2 - 7 } & p-value & 0.06 & 0.07 & 0.04 & 0.04 & 0.02 \\
\hline First difference & & & & & & \\
\hline Pesaran & t-bar & -8.267 & -4.538 & -2.679 & -2.651 & -7.783 \\
\hline \multirow{2}{*}{ Im } & p-value & 0.01 & 0.01 & 0.052 & 0.05 & 0.01 \\
\hline & t-bar p- & -14.832 & -11.479 & -12.234 & -15.025 & -15.123 \\
\cline { 3 - 7 } & value & 0 & 0 & 0 & 0 & 0 \\
\hline
\end{tabular}

The outcomes obtained from the GMM-PVAR analysis are stated in Table 2. There is a substantial and positive impact of EC and GDP on the release of $\mathrm{CO} 2$. This strongly indicates that economic development leads to an increase in air pollution in countries in the OECD region. The range of effects depend on the connection between the increased demand for natural resources in economic development. This is due to rising levels of air contamination. Hence, through the production of air pollution and waste, environmental deprivation is the primary outcome of extensive production.

Table 2. GMM-PVAR

\begin{tabular}{c|c|c|c}
\hline Model 1 & EC $(\mathbf{t}-\mathbf{1})$ & GDP $_{(\mathrm{t}-1)}$ & CO2 (t-1) \\
\hline $\mathrm{EC}(\mathrm{t})$ & 0.052 & 0.033 & 0.053 \\
& $(0.007)$ & $(0.173)$ & $(0.233)$ \\
\hline $\mathrm{GDP}(\mathrm{t})$ & 0.032 & 0.711 & 0.141 \\
& $(0.123)$ & $(0.035)$ & $(0.171)$ \\
\hline $\left.\mathrm{CO}_{2(} \mathrm{t}\right)$ & 0.088 & 0.098 & 0.913 \\
& $(0.05)$ & $(0.05)$ & $(0.05)$ \\
\hline Model 2 & $\mathrm{EC}(\mathrm{t}-1)$ & $\mathrm{GDP}_{(\mathrm{t}-1)}$ & $\mathrm{EF}(\mathrm{t}-1)$ \\
\hline $\mathrm{EC}(\mathrm{t})$ & 0.021 & 0.062 & 0.332 \\
& $(0.01)$ & $(0.247)$ & $(0.391)$ \\
\hline $\mathrm{GDP}(\mathrm{t})$ & 0.061 & 0.155 & 0.053 \\
& $(0.143)$ & $(0.03)$ & $(0.253)$ \\
\hline $\mathrm{EF}(\mathrm{t})$ & 0.037 & 0.086 & 0.162 \\
& $(0.05)$ & $(0.05)$ & $(0.032)$ \\
\hline
\end{tabular}


Moreover, the considerable impact of $\mathrm{EC}$ on $\mathrm{CO} 2$ emissions is an indication that most OECD countries are largely dependent on fossil fuel energy sources such as coal and oil. As per World Development Indicators data, in 2013 , the total EC rate of OECD countries highlighted a share of $80.5 \%$ fossil fuel consumption. Our results have been confirmed by different other studies. The findings derived from Model 2 (covered by GDP, EF, and EC variables) show a considerable connection between EC, GDP and EF. They also show a positive connection between GDP, EF and EC. These results indicate that high EC levels and economic progress lead to an increased environmental burden on OECD countries. It can also be seen that increasing economic events developed from production activities require additional natural reserves, such as land, water, soil, and energy. Similarly, an increased demand for energy precedes increased levels of EF because of the growing demand for the supply of energy, which then leads to elevated levels of $\mathrm{CO} 2$ emissions.

In the next step of the analysis, we tested the stability of each of the PVAR models used in the study (Figure 3).

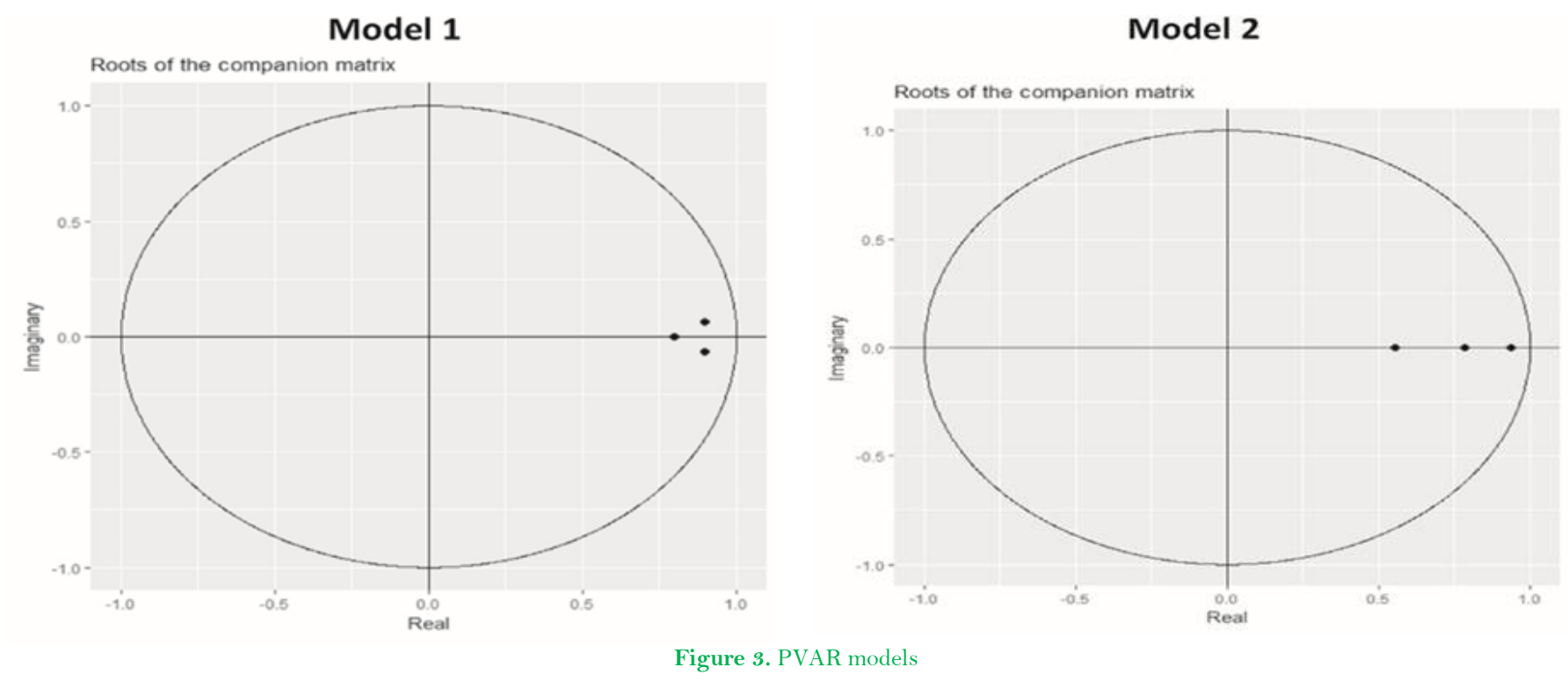

Undeniably, our results verify the fact that the stability of the variables in both models lie within the boundary of the circle. Following this process, we calculated orthogonalized impulse response function (OIRF) graphs for every model we used (Figures 4 to 6). These graphs described the reactive shocks for each of the dependent variables to the three endogenous variables evaluated over a period of two years. The confidence bands are explained with the help of the blue zone, and the red lines denote the responses. When we analyzed the connection between EC and GDP, the results revealed that EC positively reacts to the variable of GDP shocks in the first model. Similarly, in the second model, the responses were stable and positive. In the opposite relationship, the findings indicated that the variable of GDP positively responds to EC shocks in the first model; however, the impact is validated to a greater extent in the second model, as it reaches zero. With regard to the connection between pollutants and GDP, GDP presented a positive response to $\mathrm{CO} 2$ shocks. Additionally, a positive but weak response was detected between EF shocks and GDP; however, GDP did not show any response to EPI shocks. According to the findings, the responses of GDP are more evident in $\mathrm{CO} 2$ emissions, compared to the environmental indices (EPI and EF).

\section{Orthogonalized impulse response function}

OIRF and $95 \%$ confidence bands

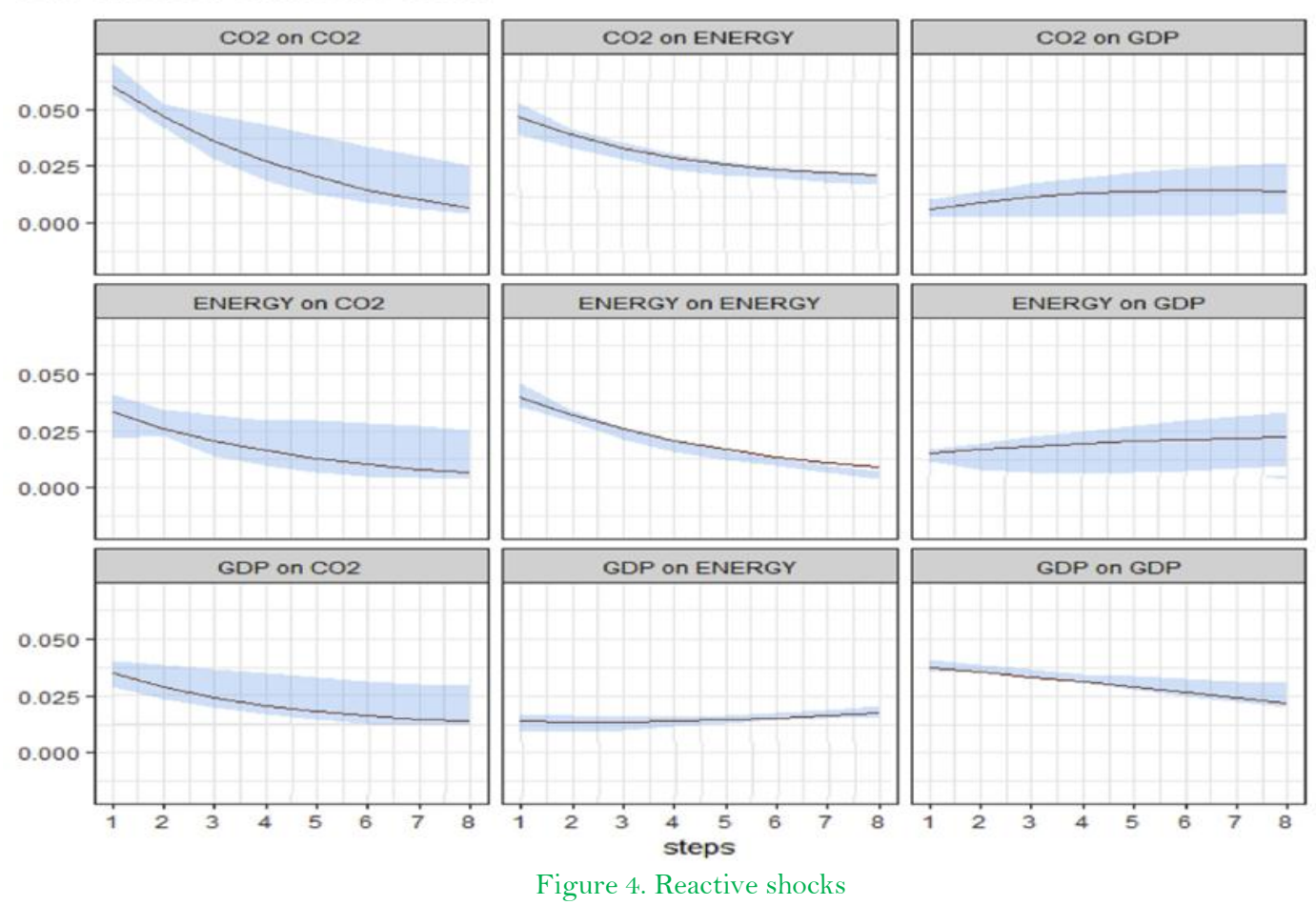

Figure 4. Reactive shocks 
Orthogonalized impulse response function

OIRF and $95 \%$ confidence bands

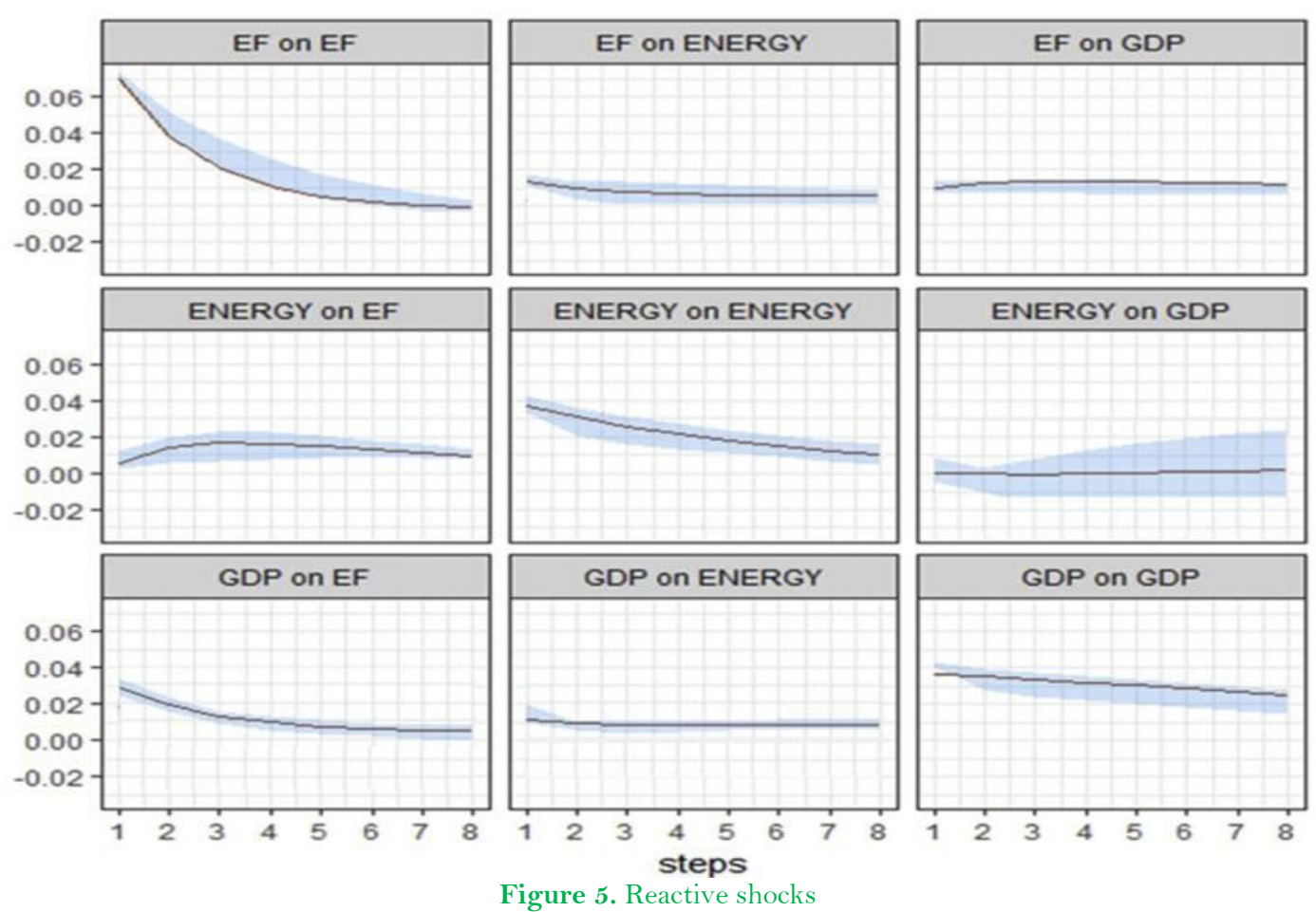

\section{Orthogonalized impulse response function}

OIRF and $95 \%$ confidence bands

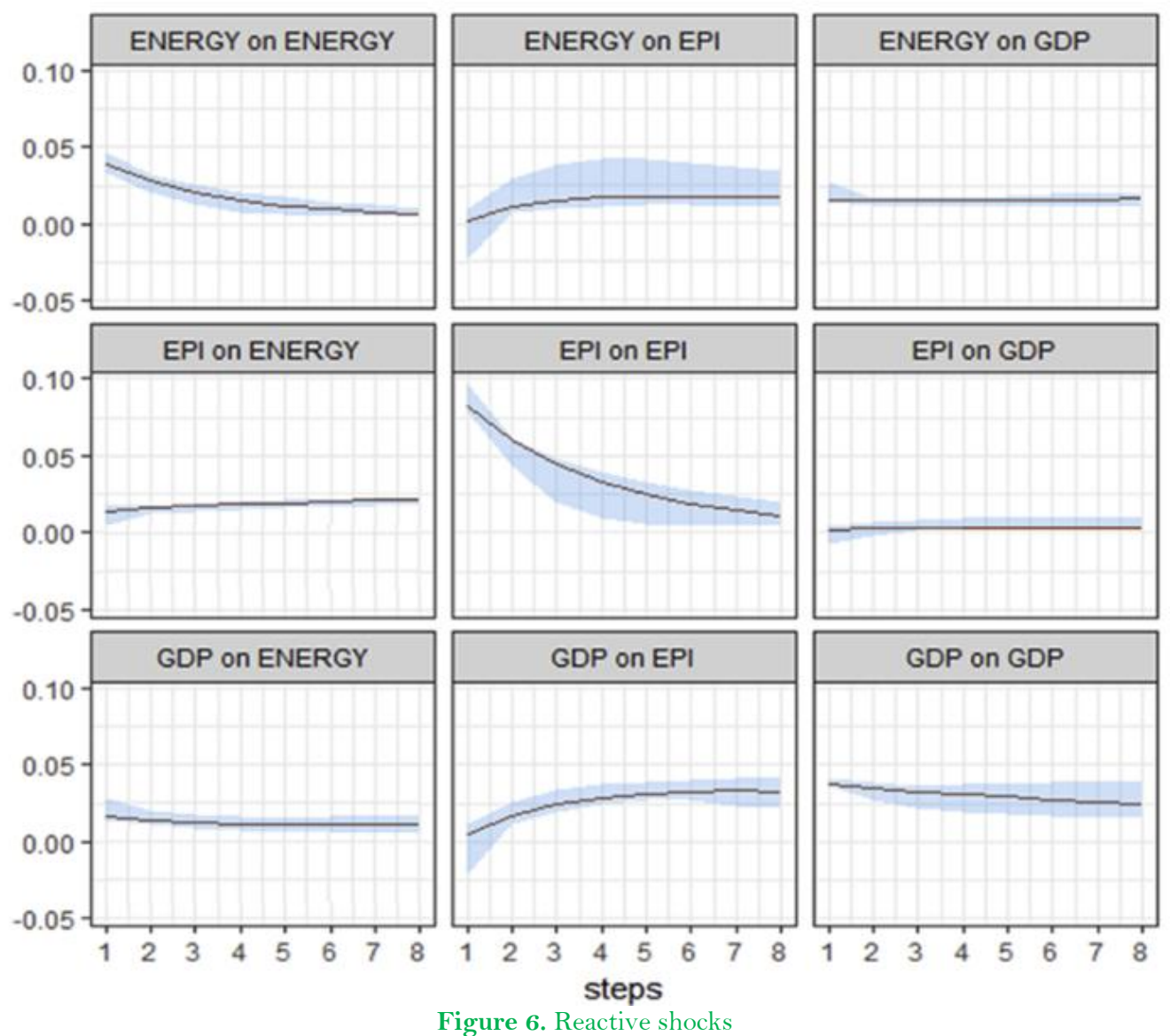

Finally, to further check the connections between the variables, we used the panel Granger causality test. The findings of the panel Granger causality test are listed in Table 3. This method of causality uses two tests to evaluate causal associations (Dumitrescu \& Hurlin, 2012). In particular, the findings of the $Z$ test and the Z-bar were found to be nearly identical. The findings indicated a bidirectional causality between the pair's EC and GDP, as well as three other variables (EPI, $\mathrm{CO} 2$ emissions, and EF).

\begin{tabular}{|c|c|c|c|c|c|c|c|c|c|c|}
\hline & Z-Wald & Z-bar & Z-Wald & Z-bar & Z-Wald & Z-bar & Z-Wald & Z-bar & $\begin{array}{l}\text { Z- } \\
\text { Wald } \\
\end{array}$ & Z-bar \\
\hline $\mathrm{EC}$ & - & - & $6.175^{*} * *$ & $12.036 * * * *$ & $5.229 * * *$ & $8.993 * * *$ & $5.733 * * *$ & $9.811 * * * *$ & $3.102^{* *}$ & $1.882^{*}$ \\
\hline $\begin{array}{l}\mathrm{GDP} \\
\mathrm{CO}_{2} \\
\end{array}$ & $\begin{array}{l}2.721^{*} \\
5.852^{* * *} *\end{array}$ & $\begin{array}{l}2.016^{*} \\
11.346^{* * *}\end{array}$ & $\begin{array}{l}- \\
10.423 * * *\end{array}$ & $\begin{array}{l}- \\
23.854 * * *\end{array}$ & $\begin{array}{l}2.279^{*} \\
-\end{array}$ & $\begin{array}{l}0.422 \\
- \\
\end{array}$ & $\begin{array}{l}2.977 \text { ** } \\
-\end{array}$ & $\begin{array}{l}2.015^{*} \\
-\end{array}$ & $\begin{array}{l}2.112^{*} \\
-\end{array}$ & $\begin{array}{l}1.266 \\
- \\
\end{array}$ \\
\hline $\mathrm{EF}$ & $4.808^{*} * * *$ & $7.243 * * *$ & $8.046^{* * * *}$ & $16.362 * * * *$ & - & - & - & - & - & - \\
\hline EPI & 4.746 **** & $6.655^{*} * * *$ & $2.902^{*} * * *$ & $2.122 *$ & - & - & - & - & - & - \\
\hline
\end{tabular}




\section{Discussion and Conclusion}

This research uses estimations from the GMM-PVAR method to explore the causal relationships between EG, $\mathrm{CO} 2$ emissions, EC, and environmental indices (EPI or EF). This methodology was applied to a panel of thirty-five OECD countries between 2000 and 2014. Furthermore, the study estimated the interconnections between variables using the panel Granger causality test. The findings obtained from the PVAR-GMM test indicate a considerable positive impact on GDP and EC on the overall quality of environmental statistics ( $\mathrm{CO} 2$ emissions, EF and EPI). Growing economic developments following industrial development and manufacturing produces more $\mathrm{CO} 2$ emissions and creates extra pressure on the environment. Rising levels of EPI indicate that a shift in countries' EG will affect economic performance. Across the observed time period, it became evident that OECD countries regularly changed their EC models by moving towards renewable energy resources. Moreover, findings from the panel causality tests validated a bidirectional relationship between all variables except for the following pairs: $\mathrm{CO} 2$ and GDP and EPI and GDP. In these instances, we discovered encouraging support for unidirectional causality shifting from GDP to the other two statistics. The results of the present study are supported by similar studies (Le, 2019; Ozcan, Tzeremes, \& Tzeremes, 2020; Phrakhruopatnontakitti, Watthanabut, \& Jermsittiparsert, 2020). The study by Phrakhruopatnontakitti et al. (2020) evaluated causal associations between the emissions of pollutants, EC patterns, and economic output using panel data that considered four ASEAN countries. Pollutant emissions and environmental degradation is uncharacteristically high in the ASEAN region. The results of the study indicated that, in the long-term, energy consumption patterns were significantly correlated with $\mathrm{CO} 2$ emissions. In the short-term, changes in emission patterns were also found to be significant. The study by Cai, Sam, and Chang (2018) evaluated causal associations between consumption patterns of clean energy, EG and $\mathrm{CO} 2$ emissions. The study used an ARDL bounds methodology to analyze the EC and pollutant emission patterns of G7 countries. The results of the causality analysis shows the presence of unidirectional causality between clean EC patterns and GDP per capita. These studies support the findings of this study, showing that economic degradation can be supplemented by limiting environmental pollutants.

The route towards ecological improvements can be indicated as countries' benchmark for collaboration instead of a tradeoff between economic development and the natural environment. The major focus of policies related to sustainable economic progress is the foundation of an integrated working program between trade and industry expansion and the atmosphere. The findings generated by this study suggest the necessity of a collaborative relationship between the natural environment and economic advancement goals in OECD countries. This is because many OECD economies are causing harm to their economy through their energy patterns and their environmental strategies. The results from the estimations of the GMM- PVAR model outlined the significant and positive impact of EG and $\mathrm{EC}$ on the indicators used for the quality of the environment. The economic activities of countries are increasing due to industrialization, which produces strong emissions of pollutants, which cause harm to the environment.

Theis study also has some limitations and policy implications. The main focus of the study was OECD countries and their environmental sustainability. This domain has been the focus of researchers for some time now; however, the application of models like the PVAR-GMM to evaluate such associations has been limited. Thus, contributions to the existing literature have been made. The policymakers of institutions responsible for pollutant emissions can evaluate the results of this study and formulate policies to make the environment safer and reduce degradation. The time frame of this study was constrained, as the original dataset measured EG and degradation for only 14 years. Moreover, the data was only employed in the OECD region. Thus, future researchers should focus on increasing the sample size and diversifying the sample by including other regions, in order for the results to be more generalized.

\section{References}

Adu, D. T., \& Denkyirah, E. K. (2018). Economic growth and environmental pollution in West Africa: Testing the Environmental Kuznets Curve hypothesis. Kasetsart Journal of Social Sciences.

Ahmad, A. U., Ismail, S., Jakada, A. H., Farouq, I. S., Muhammad, A. A., Mustapha, U. A., . . Muhammad, A. (2020). A heterogeneous relationships between Urbanization, energy consumption, economic growth on environmental degradation: Panel study of Malaysia and selected ASEAN+ 3 Countries. Journal of Environmental Treatment Techniques, 8(1), 573-581.

Alvarado, R., Ponce, P., Criollo, A., Córdova, K., \& Khan, M. K. (2018). Environmental degradation and real per capita output: New evidence at the global level grouping countries by income levels. Journal of Cleaner Production, 189, 13-20. Available at: https://doi.org/10.1016/j.jclepro.2018.04.064.

Alvarado, R., \& Toledo, E. (2017). Environmental degradation and economic growth: Evidence for a developing country. Environment, Development and Sustainability, 19(4), 1205-1218. Available at: https://doi.org/10.1007/s 10668-016-9790-y.

Amir, M., \& Chaudhry, N. I. (2019). Linking environmental strategy to firm performance: A sequential mediation model via environmental management accounting and top management commitment. Pakistan Journal of Commerce and Social Sciences (PJCSS), 13(4), 849867.

Balsalobre-Lorente, D., Driha, O. M., Shahbaz, M., \& Sinha, A. (2020). The effects of tourism and globalization over environmental degradation in developed countries. Environmental Science and Pollution Research, 27(7), 7130-7144. Available at: https://doi.org/10.1007/s11356-019-07372-4.

Balsalobre-Lorente, D., Shahbaz, M., Roubaud, D., \& Farhani, S. (2018). How economic growth, renewable electricity and natural resources contribute to $\mathrm{CO} 2$ emissions? Energy Policy, 113, 356-367. Available at: https://doi.org/10.1016/j.enpol.2017.10.050.

Bekhet, H. A., Matar, A., \& Yasmin, T. (2017). CO2 emissions, energy consumption, economic growth, and financial development in GCC countries: Dynamic simultaneous equation models. Renewable and Sustainable Energy Revierws, 70, 117-132. Available at: https://doi.org/10.1016/j.rser.2016.11.089.

Cai, Y., Sam, C. Y., \& Chang, T. (2018). Nexus between clean energy consumption, economic growth and CO2 emissions. Journal of Cleaner Production, 182, 1001-1011. Available at: https://doi.org/10.1016/j.jclepro.2018.02.035.

Destek, M. A., \& Sinha, A. (2020). Renewable, non-renewable energy consumption, economic growth, trade openness and ecological footprint: Evidence from organisation for economic Co-operation and development countries. Journal of Cleaner Production, 242, 118537

Dumitrescu, E.-I., \& Hurlin, C. (2012). Testing for Granger non-causality in heterogeneous panels. Economic Modelling, 29(4), 1450-1460. Available at: https://doi.org/10.1016/j.econmod.2012.02.014.

Gorus, M. S., \& Aydin, M. (2019). The relationship between energy consumption, economic growth, and CO2 emission in MENA coun tries: Causality analysis in the frequency domain. Energy, 168, 815-822. Available at: https://doi.org/10.1016/j.energy.2018.11.139. 
Hsu, A., Lloyd, A., \& Emerson, J. W. (2013). What progress have we made since Rio? Results from the 2012 Environmental Performance Index (EPI) and Pilot Trend EPI. Environmental Science \& Policy, 33, 171-185. Available at: https://doi.org/10.1016/j.envsci.2013.05.011.

Im, K. S., Pesaran, M. H., \& Shin, Y. (2003). Testing for unit roots in heterogeneous panels. Journal of Econometrics, 115(1), 53-74. Available at: https://doi.org/10.1016/s0304-4076(03)00092-7.

Kahouli, B. (2019). Does static and dynamic relationship between economic growth and energy consumption exist in OECD countries? Energy Reports, 5, 104-116. Available at: https://doi.org/10.1016/j.egyr.2018.12.006.

Le, D. N. (2019). Environmental degradation and economic growth in ASEAN-10: The perspective of EKC hypothesis. Malaysian Journal of Economic Studies, 56(1), 43-62. Available at: https://doi.org/10.22452/mjes.vol56no1.3.

Majeed, M. T., \& Luni, T. (2019). Renewable energy, water, and environmental degradation: A global panel data approach. Pakistan Journal of Commerce and Social Sciences (PJCSS), 13(3), 749-778.

Majeed, M. T., \& Mumtaz, S. (2017). Happiness and environmental degradation: A global analysis. Pakistan Journal of Commerce and Social Sciences (PJCSS), $11(3), 753-772$.

Mbarek, M. B., Saidi, K., \& Rahman, M. M. (2018). Renewable and non-renewable energy consumption, environmental degradation and economic growth in Tunisia. Quality \& Quantity, 52(3), 1105-1119. Available at: https://doi.org/10.1007/s 11135-017-0506-7.

Ogundipe, A. A., Obi, S., \& Ogundipe, O. M. (2020). Environmental degradation and food security in Nigeria. International Journal of Energy Economics and Policy, 10(1), 316-324.

Oktavilia, S., \& Firmansyah, F. The relationships of environmental degradation and trade openness in Indonesia. International Journal of Economics and Financial Issues, 6(6S), 125-129.

Ozcan, B., Tzeremes, P. G., \& Tzeremes, N. G. (2020). Energy consumption, economic growth and environmental degradation in OECD countries. Economic modelling, 84, 203-2 13. Available at: https://doi.org/10.1016/j.econmod.2019.04.010.

Pesaran, M. H. (2007). A simple panel unit root test in the presence of cross-section dependence. Journal of Applied Econometrics, 22(2), 265312. Available at: https://doi.org/10.1002/jae.951.

Phrakhruopatnontakitti, P., Watthanabut, B., \& Jermsittiparsert, K. (2020). Energy consumption, economic growth and environmental degradation in 4 Asian countries: Malaysia, Myanmar, Vietnam and Thailand. International Journal of Energy Economics and Policy, 10(2), 529-539. Available at: https://doi.org/10.32479/ijeep.9229.

Rahman, M. M. (2020). Environmental degradation: The role of electricity consumption, economic growth and globalisation. Journal of Environmental Management, 253, 109742.

Raza, S. A., Shah, N., \& Sharif, A. (2019). Time frequency relationship between energy consumption, economic growth and environmental degradation in the United States: Evidence from transportation sector. Energy, 173, 706-720. Available at: https://doi.org/10.1016/j.energy.2019.01.077.

Saidi, S., \& Hammami, S. (2017). Modeling the causal linkages between transport, economic growth and environmental degradation for 75 countries. Transportation Research Part D: Transport and Environment, 53, 415-427. Available at: https://doi.org/10.1016/j.trd.2017.04.031.

Sekrafi, H., \& Sghaier, A. (2018). Examining the relationship between corruption, economic growth, environmental degradation, and energy consumption: A panel analysis in MENA region. Journal of the Knowledge Economy, 9(3), 963-979. Available at: https://doi.org/10.1007/s13132-016-0384-6.

Sharif, A., Mishra, S., Sinha, A., Jiao, Z., Shahbaz, M., \& Afshan, S. (2020). The renewable energy consumption-environmental degradation nexus in Top-10 polluted countries: Fresh insights from quantile-on-quantile regression approach. Renewable Energy, 150, 670-690. Available at: https://doi.org/10.1016/j.renene.2019.12.149.

Sharif, A., \& Raza, S. A. (2016). Dynamic relationship between urbanization, energy consumption and environmental degradation in Pakistan: Evidence from structure break testing. Journal of Management Sciences, 3(1), 1-21. Available at: https://doi.org/10.20547/jms.2014.1603101.

Sinha, A., Shahbaz, M., \& Balsalobre, D. (2017). Exploring the relationship between energy usage segregation and environmental degradation in $\mathrm{N}-11$ countries. Journal of Cleaner Production, 168, 1217-1229. Available at: https://doi.org/10.1016/j.jclepro.2017.09.071.

Usman, O., Olanipekun, I. O., Iorember, P. T., \& Abu-Goodman, M. (2020). Modelling environmental degradation in South Africa: the effects of energy consumption, democracy, and globalization using innovation accounting tests. Environmental Science and Pollution Research, 27(8), 8334-8349. Available at: https://doi.org/10.1007/s11356-019-06687-6.

Usman, O., Alola, A. A., \& Sarkodie, S. A. (2020). Assessment of the role of renewable energy consumption and trade policy on environmental degradation using innovation accounting: Evidence from the US. Renewable Energy, 150, $266-277$.

Zafar, M. W., Saud, S., \& Hou, F. (2019). The impact of globalization and financial development on environmental quality: evidence from selected countries in the Organization for Economic Co-operation and Development (OECD). Environmental Science and Pollution Research, 26(13), 13246-13262.

Zafar, M. W., Shahbaz, M., Sinha, A., Sengupta, T., \& Qin, Q. (2020). How renewable energy consumption contribute to environmental quality? The role of education in OECD countries. Journal of Cleaner Production, 122149. 